\title{
Karaciğer Fibrokistik Hastalıklarının Değerlendirilmesi; Tek Merkez Deneyimi
}

\author{
Evaluation of Fibrocystic Diseases of Liver; Single Center \\ Experience
}

\author{
Elif SAĞ${ }^{1}$, Burcu GÜVEN ${ }^{1}$, Sefa SAĞ ${ }^{2}$, H. Sonay YALÇIN CÖMERT ${ }^{3}$, Elif BAHAT ÖZDOĞAN${ }^{4}$, \\ Illker EYÜPOĞLU ${ }^{5}$, Alper Han ÇEB| ${ }^{6}$, Yakup ARSLAN ${ }^{7}$, Murat ÇAKIR ${ }^{1}$
}

\begin{abstract}
${ }^{1}$ Karadeniz Teknik Üniversitesi, Tıp Fakültesi, Çocuk Sağlığı ve Hastalıkları Anabilim Dalı, Çocuk Gastroenteroloji, Hepatoloji ve Beslenme Bilim Dalı, Trabzon, Türkiye

${ }^{2}$ Sağlık Bilimleri Üniversitesi, Kanuni Eğitim ve Araştırma Hastanesi, Çocuk Cerrahi Bölümü, Trabzon, Türkiye

${ }^{3}$ Karadeniz Teknik Üniversitesi, Tıp Fakültesi, Cerrahi Anabilim Dall, Çocuk Cerrahi Bilim Dalı, Trabzon, Türkiye

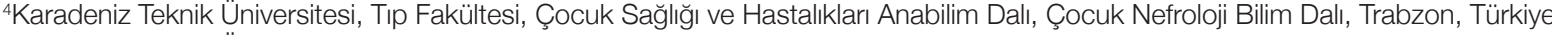

${ }^{5}$ Karadeniz Teknik Üniversitesi, Tıp Fakültesi, Dahili Anabilim Dalı, Radyoloji Bilim Dalı, Trabzon, Türkiye

${ }^{6}$ Karadeniz Teknik Üniversitesi, Tıp Fakültesi, Dahili Anabilim Dall, Genetik Bilim Dalı, Trabzon, Türkiye

${ }^{7}$ Karadeniz Teknik Üniversitesi, Tıp Fakültesi, Çocuk Sağlığı ve Hastalıkları Anabilim Dal, Yenidoğan Bilim Dalı, Trabzon, Türkiye
\end{abstract}

\section{ÖZ}

Amaç: Karaciğerin fibrokistik hastalığı (KFKH), intrauterin dönemden adölesan yaşa kadar geniş bir yaș aralı̆̆ında görülebilen, multisistemik bir hastalıktır. Çalışmadaki amacımız; kliniğimizde KHFK olan hastaların, başvuru semptomları, klinik-laboratuvar bulguları, tedavi yaklaşımı ve takip sonuçlarını değerlendirmektir.

Gereç ve Yöntemler: Ocak 2008-Aralık 2019 yılları arasında, Çocuk Gastroenteroloji, Hepatoloji ve Beslenme polikliniğinde KFKH nedeniyle takipli olan hastaların; demografik özellikleri, klinik-laboratuar bulguları, tedavi yaklaşımları ve son durumları geriye dönük olarak incelendi.

Bulgular: Otuz dokuz hastanın (\%56.4 erkek, ortanca yaş; 5 yı 3 ay, yaş aralığı: 10 gün-6.8 yıl) sekizinde (\%20.5) Caroli hastalığı (CH), 16'sında (\%41) konjenital hepatik fibrozis (KHF), 15'inde koledok kisti tespit edildi. En sık başvuru şikayeti; sarııı ( $n=8, \% 20.5)$, kronik karın ağrısı ( $n=6, \% 15.4)$ ve splenomegali $(n=4, \% 10.3)$ 'dü. Hastaların sekizi (\%20.5) böbrekte kist tespit edildikten sonra yapılan incelemelerde, yedisi (\%17.9) intrauterin dönemde, ikisi (\%5.1) insidental olarak tespit edilmişti. Otozomal resesif polikistik böbrek hastalığı (ORPBH) olan altı hastada PKHD1 gen mutasyonu saptandı. On sekiz hasta (\%46.2) opere edildi (karaciğer nakli, sol lob segmental hepatektomi, mezokavalşant, böbrek nakli, kistektomi). Yirmi beș hastada (\%64.1) ekstrahepatik tutulum mevcuttu [ORPBH $(n=18)$, mental motor retardasyon ( $n=2$, birinde metokromatik lökodistrofi, diğerinde Arnold Chiari malformasyonu), nefrokalsinozis $(n=1)$, juvenil nefronofitizis ( $n=1)$, akut pankreatit $(n=1)$, pulmoner hipoplazi+metakarpal distal falanks hipoplazisi $(n=1)$ ve medüler sünger böbrek+pineal kist $(n=1)]$. Takip edilen 39 hastanın; altısında portal hipertansiyon, beşinde kronik böbrek yetmezliği (\%12.8), dördünde kompanse kronik karaciğer hastalığı (\%10.3) gelişmiş olup iki hastaya dekompanse siroz nedeniyle karaciğer nakli, bir hastaya son dönem böbrek yetmezliği nedeniyle böbrek nakli yapıldı.

Sonuç: Karaciğerin fibrokistik hastalıklarında, morbidite ve komplikasyon riskinin yüksek olması nedeniyle erken tanı, düzenli takip ve tedavi önemlidir.

Anahtar Sözcükler: Çocuk, Fibrokistik, Karaciğer

(1)

SAĞE

GÜVEN B

SAĞ S

YALÇIN CÖMERT HS

BAHAT ÖZDOĞAN E

EYÜPOĞLUI

ÇEBI AH

ARSLANY

ÇAKIR M
0000-0003-3069-2872 0000-0002-5142-8168 $0000-0002-0904-315 X$ 0000-0002-5281-4933 $0000-0002-9785-8067$ 0000-0002-9867-8666 0000-0001-7388-874X 0000-0001-9833-8840 0000-0001-8789-8199
Çıkar Çatışması / Conflict of Interest: Tüm yazarlar adına, sorumlu yazar çıkar çatışması olmadığııı belirtir.

Etik Kurul Onayı / Ethics Committee Approval: Bu çalısmada ulusal ve uluslararası etik kurallara uyulmuștur. Çalıșma için 2018/262 nolu etik kurul onayı alınmıştır. Kayıt sırasında veliler tarafından araşıımaya katıım için bilgilendirilmiş bir onay imzalanmışıı.

Yazarların katkısı / Contribution of the Authors: SAĞ E: Yazının dizaynı, planlanması, verilerin toplanması, literatür araștırması, istatistik yapılması, yazının yazıması ve yayın için son onayın verilmesi. GÜVEN B: Literatür araștırması, verilerin toplanması, ișlenmesi, analizi ve yorumlanması. SAĞ S: Verilerin toplanması, cerrahi prosedürün değerlendirilmesi, yayın için son onayın verilmesi. YALÇIN CÖMERT HS: Verilerin toplanması, cerrahi prosedürün değerlendirilmesi, yayın için son onayın verilmesi, BAHAT ÖZDOĞAN E: Verilerin değerlendirilmesi, yazının kontrolü, yayın için son onayın verilmesi. EYÜPOĞLU $\boldsymbol{i}$ : Verilerin toplanması ve radyolojik değerlendirilmesinin yapılması, yayın için son onayın verilmesi. ÇEBi H: Genetik verilerin verilmesi. EYUPOGLU i: Verilerin toplanması ve radyolojik değerlendirilmesinin yapılması, yayın için son onayın verilmesi. ÇEBI H: Genetik verilerin yapılması ve değerlendirilmesi, yayın için son onayın verilmesi Verilerin toplanması ve radyolojik değerlendirilmesinin yapılması, yayın için son onayın
verilmesi. ARSLAN Y: Verilerin değerlendirilmesi, yazının kontrolü, yayın için son onayın verilmesi. ÇAKIR M: Yazının dizaynı, planlanması, yazının değerlendirilmesi, yayın için son onayın verilmesi.

Atıf yazım şekli / How to cite : Sağ E, Güven B, Sağ S, Yalçın Cömert HS, Bahat Özdoğan E, Eyüpoğlu I, Çebi H, Arslan Y, Çakır M. Karaciğer Fibrokistik Hastalıklarının Değerlendirilmesi; Tek Merkez Deneyimi. Türkiye Çocuk Hast Derg 2020;14:391-395.
Yazışma Adresi / Correspondence Address:

Elif SAĞ

Karadeniz Teknik Üniversitesi, Tıp Fakültesi, Çocuk Sağlığı ve Hastalıkları Anabilim Dalı,

Çocuk Gastroenteroloji, Hepatoloji ve Beslenme Bilim Dalı, Trabzon, Türkiye

E-posta: drturkmen61@gmail.com
Geliş tarihi / Received : 02.01.2020 Kabul tarihi / Accepted : 27.05 .2020 Elektronik yayın tarihi : 17.09 .2020 Online published

DOI: $10.12956 /$ tchd.662772 


\section{ABSTRACT}

Objective: Fibrocystic liver disease (FLD) is a multisystemic disease that can be seen in a wide age range from intrauterine period to adolescent age. The aim of study is to evaluate the presenting symptoms, clinical-laboratory findings, treatment modality and results of the patients with FLD .

Material and Methods: The demographic features, clinical-laboratory findings, treatment modality and results of patients with FLD followed up in our clinic between January 2008 and December 2019 were recorded retrospectively.

Results: A total of 39 patients (56.4\% male, median age; 53m years, age range: 10 days-16.8 years) were evaluated. Eight patients (20.5\%) had Caroli's disease (CD), 16 patients had congenital hepatic fibrosis (CHF) (41\%), and 15 had choledochal cysts. The most common presenting symptoms were jaundice $(n=8,20.5 \%)$, chronic abdominal pain $(n=6,15.4 \%)$ and splenomegaly $(n=4,10.3 \%)$. Eight patients were detected after renal cyst detection and screening programme (20.5\%), seven patients during intrauterine period (17.9\%), and two patients incidentally (5.1\%). PKHD1 gene mutation was deteceted in six patients with autosomal recessive polycystic kidney disease (ARPKD). Eighteen patients underwent surgical operation (46.2\%, liver transplantation, left lobe segmental hepatectomy, mesocaval shunt, kidney transplantation, cystectomy). 25 patients (64.1\%) had extrahepatic involvement [ ARPKD ( $n=18)$, mental motor retardation ( $n=2$, methochromatic leukodystrophy, Arnold Chiari malformation in each one), nephrocalcinosis $(n=1)$, juvenile nephronophytosis $(n=1)$ acute pancreatitis $(n=1)$, pulmonary hypoplasia + metacarpal distal phalanx hypoplasia $(n=1)$ and medullary sponge kidney+pineal cyst $(n=1)$ ]. During the follow up of 39 patients; six patients had portal hypertension, five had chronic renal failure (12.8\%), four had compensated chronic liver disease (10.3\%) and one had recurrent cholangitis attacks (2.6\%). Two patients underwent liver transplantation due to decompensated cirrhosis, and one patient underwent kidney transplantation due to end-stage renal failure.

Conclusion: Early diagnosis, regular follow-up and treatment are important in patients with FLD because of the high risk of morbidity and complications.

Key Words: Child, Fibrocystic, Liver

\section{GiRiş}

Karaciğerin fibrokistik hastalıkları (KFKH); intrahepatik ve/ veya ekstrahepatik biliyer anormallikler sonucunda safra kanallarında genişleme, hepatik fibrozis ve kistik oluşumlarla karakterize, otozomal resesif veya dominant geçişli olabilen heterojen ve nadir görülen bir hastalık grubudur. Çoğunlukla kalitsal olmasına rağmen bazı olgular sporadik olarak görülebilmektedir. Büyük safra kanallarının tutulumunda koledok kisti (KK, ekstrahepatik kanal) ve Caroli hastalığı $(\mathrm{CH}$, intrahepatik kanal), orta safra kanallarının tutulumunda otozomal dominant polikistik karaciğer hastalığı (ODPKH), küçük safra kanallarının tutulumunda ise konjenital hepatik fibrozis (KHF) ve bilier hamartom oluşmaktadır (1). Hastalar asemptomatik olabilir veya kolanjit, portal hipertansiyon (PHT), siroz, ele gelen kitle gibi bulgularla başvurabilirler. KHF izole görülebildiği gibi multisistemik tutulumların olduğu genetik sendromlarla birlikte de görülebilmektedir (2). Bunun yanında, KFKH'ye sıklıkla otozomal resesif polikistik böbrek hastalığı (ORPBH), medüller sünger böbrek ve nefronofitizis gibi siliopati sonucu gelişen renal hastalıklar eşlik edebilmektedir (3).

Karaciğerin fibrokistik hastalıklarının patogenezinde siliyopati ve duktal plak malformasyonu rol oynamaktadır. Duktal plak, gebeliğin 6. ve 7. haftası arasında oluşan, embriyonun gelişmesi ve gebeliğin sonlanmasıyla kaybolan bir yapıdır. Normal embriyogenez sırasında duktal plak, portal venin bir dalını çevreleyen yarık benzeri, lümenli, silindirik, çift katmanlı bir kolanjiyosit kümesi olarak gelişir ve silindirik duktal plakların gelişimi sonucunda ise safra kanalları oluşmaktadır (3). Polycystin (PC) 1 ve PC2, normal siliyer aktivite için gerekli fonksiyonel bir proteindir. PC1 ve PC2'nin mutasyonu sonucu siliyopati meydana gelir ve remodeling esnasında apopitozis-proliferasyon arasındaki denge bozularak duktal plak malformasyonuna yol açar (4). Anormal apoptoz, SIVI sekresyonu ve ekstraselüler matrix birikimi ile birlikte epitelyal safra kanallarının proliferasyonu ve dilatasyonu sonucu kistik oluşumlar görülmektedir (5).

Çoklu organ tutulumunun sık görüldüğü, uzun dönem komplikasyon ve morbidite oranı yüksek olan bu hastalık grubunda erken tanı ve tedavi hastanın yaşam kalitesi açısından önemlidir. Çalışmadaki amacımız; kliniğimizde takip edilen KFKH'li hastaların, başvuru semptomları, klinik-laboratuvar bulguları, tedavi yaklaşımı ve takip sonuçların değerlendirmektir.

\section{GEREÇ ve YÖNTEMLER}

Çalışmamıza; Ocak 2008-Aralık 2019 yılları arasında, Karadeniz Teknik Üniversitesi Tıp Fakültesi Çocuk Gastroenteroloji, Hepatoloji ve Beslenme polikliniğinde $\mathrm{KFKH}$ nedeniyle takipli olan hastaların; demografik özellikleri, klinik-laboratuar bulguları, tedavi yaklaşımları ve son durumları geriye dönük olarak incelendi. Çalışma için Karadeniz Teknik Üniversitesi Etik Kurul'undan 2018/262 nolu etik kurul onayı alınmıştır.

İstatiksel analizler "SPSS $®$ for Windows version 16.0" kullanılarak yapıldı. Değerlendirme sonuçlarının tanımlayıcı istatistikleri; kategorik değişkenler için sayı ve yüzde, sayısal değişkenler için ortanca, minimum-maksimum, olarak verildi.

\section{BULGULAR}

Çalışmada toplam 39 hasta incelendi (\%56.4 erkek, ortanca yaş; 5 yıl 3 ay, yaş aralığl: 10 gün-16.8yll). Sekiz hastada (\%20.5) CH, 
Tablo I: Karaciğerin fibrokistik hastalı̆ı olan hastaların demografik özellikleri, klinik-laboratuvar bulguları, tedavi yaklaşımları ve son durumları.

\begin{tabular}{|c|c|c|c|}
\hline & $\begin{array}{c}\mathrm{CH} \\
\mathrm{n}=8\end{array}$ & $\begin{array}{l}\text { KHF } \\
\mathrm{n}=16\end{array}$ & $\begin{array}{c}\mathrm{KK} \\
\mathrm{n}=15\end{array}$ \\
\hline Cinsiyet, E, n (\%) & $5(62.5)$ & 9 (56.3) & $8(53.3)$ \\
\hline Yaş, ay, ortanca (minimum-maksimum) & $\begin{array}{c}2 \\
\text { (10 gün-16.8 yıl) }\end{array}$ & $\begin{array}{c}5.8 \\
(1 \text { ay-15 yll) }\end{array}$ & $\begin{array}{c}5.3 \\
(1 \text { ay-13.9 yıl) }\end{array}$ \\
\hline $\begin{array}{l}\text { Başvuru şikayeti, } \mathbf{n} \text { (\%) } \\
\text { Splenomegali } \\
\text { Prenatal tanı } \\
\text { Renal kist tarama } \\
\text { Kolanjit atağı } \\
\text { Varis kanama } \\
\text { Transaminaz yüksekliği } \\
\text { Insidental } \\
\text { Sarılık } \\
\text { Karın ağrısı }\end{array}$ & $\begin{array}{c}2(25) \\
- \\
5(62.5) \\
- \\
- \\
1(12.5) \\
- \\
-\end{array}$ & $\begin{array}{l}4(25) \\
4(25) \\
3(18.8) \\
1(6.3) \\
1(6.3) \\
1(6.3) \\
1(6.3) \\
1(6.3) \\
\quad-\end{array}$ & $\begin{array}{l}1(6.7) \\
- \\
1(6.7) \\
- \\
- \\
- \\
7(46.7) \\
6(40)\end{array}$ \\
\hline $\begin{array}{l}\text { Eşlik eden hastalık, } \mathbf{n}(\%) \\
\text { ORPBH } \\
\text { Medüller sünger böbrek } \\
\text { Nefronofitizis } \\
\text { MMR+ACM } \\
\text { MMR+MLD } \\
\text { Nefrokalsinozis } \\
\text { Pulmoner hipoplazi+MDF hipoplazi } \\
\text { Pankreatit } \\
\text { Pineal kist }\end{array}$ & $\begin{array}{c}7(87.5) \\
- \\
- \\
1(12.5) \\
- \\
1(12.5) \\
- \\
- \\
-\end{array}$ & $\begin{array}{c}11(68.8) \\
1(6.3) \\
1(6.3) \\
- \\
1(6.3) \\
- \\
1(6.3) \\
- \\
1(6.3)\end{array}$ & $\begin{array}{c}- \\
- \\
- \\
- \\
- \\
- \\
- \\
1(6.7) \\
-\end{array}$ \\
\hline $\begin{array}{l}\text { Yapılan cerrahi müdaheleler } \\
\text { Böbrek nakli } \\
\text { Karaciğer nakli } \\
\text { Sol lateral hepatektomi } \\
\text { Roux-En-Y operasyonu } \\
\text { Kisto-enterostomi } \\
\text { Kistektomi ve T tüp drenaj } \\
\text { Mezokaval şant } \\
\text { Band ligasyonu }\end{array}$ & $\begin{array}{c}- \\
1(12.5)^{\star} \\
- \\
- \\
- \\
- \\
- \\
-\end{array}$ & $\begin{array}{l}1(6.3) \\
1(6.3) \\
1(6.3) \\
- \\
- \\
- \\
1(6.3) \\
3(18.9)\end{array}$ & $\begin{array}{c}- \\
- \\
- \\
11(73.3) \\
1(6.7) \\
1(6.7) \\
- \\
-\end{array}$ \\
\hline $\begin{array}{l}\text { Son durum } \\
\text { Kronik hepatit } \\
\text { PHT } \\
\text { KBY } \\
\text { Asemptomatik } \\
\text { Eksitus } \\
\text { Takipsiz }\end{array}$ & $\begin{array}{l}2(25) \\
1(12.5)^{\star} \\
2(25) \\
2(25) \\
2(25) \\
\quad-\end{array}$ & $\begin{array}{l}2(12.5) \\
5(31.2) \\
3(18.9) \\
8(50) \\
1(6.3) \\
\quad-\end{array}$ & $\begin{array}{c}- \\
- \\
- \\
- \\
- \\
2(13.3)\end{array}$ \\
\hline
\end{tabular}

ACM: Arnold Chiari malformasyonu, $\mathbf{C H}$ : Caroli hastalığı, KBY: kronik böbrek yetmezliği, $\mathbf{P H T : ~ p o r t a l ~ h i p e r t a n s i y o n , ~} \boldsymbol{K H F}$ : konjenital hepatik fibrozis, KK: koledok kisti, MMR: mental motor retardasyon, MDF: metakarpal distal falanks, $\mathbf{M L D}$ : metakromatik lökodistrofi, ORPBH: otozomal resesif polikistik böbrek hastalığı, *: Caroli sendromu: $\mathrm{CH}+\mathrm{PHT}$

16 hastada KHF (\%41), 15 hastada KK (\%38.5; dokuz hastada tip I, beş hastada tip IV, bir hastada tip III) tespit edilmiş olup bilier hamartom ve ODPKH olan hasta yoktu. Başvuru şikayeti; sekiz hastada sarlık (\%20.5), altı hastada kronik karın ağrısı (\%15.4), dört hastada splenomegali (\%10.3), iki hastada akut kolanjit atağı (\%5.1), bir hastada transaminaz yüksekliği (\%2.6) ve bir hastada varis kanaması (\%2.6)'dı. Sekiz hasta böbrekte kist tespit edildikten sonra tarama amaçı incelemede (\%20 .5), yedi hasta intrauterin dönemde (\%17.9), iki hasta ise hiçbir semptomu olmadan insidental olarak tespit edilmişti (\%5.1).

Konjenital hepatik fibrozis olan 16 hastanın 12'si primer KHF, dördü ise sendromik KHF olarak tanımlandı [metokromatik lökodistrofi ( $n=1)$, sendromik ( $n=1$, pulmoner hipoplazi, metakarpal distal falanks hipoplazisi), Joubert sendromu $(n=2)]$.

Yirmi beş hastada (\%64.1) ekstrahepatik tutulum mevcuttu; 18 hastada (\% 46.2) ORPBH, iki hastada mental motor retardasyon [\%5.1; metokromatik lökodistrofi $(n=1)$, Arnold Chiari malformasyonu $(\mathrm{n}=1)$ ], birer hastada (\%2.6) nefrokalsinozis, juvenil nefronofitizis, akut pankreatit, medüler sünger böbrek+pineal kist ve pulmoner hipoplazi+metakarpal distal falanks hipoplazisi mevcuttu. Multisistemik tutulum en sık KHF olan hastalarda izlendi.

On sekiz hastaya cerrahi operasyon uygulandı (\%46.2). KHF olan dört hasta [\%10.3, karaciğer nakli $(n=1)$, sol lob segmental 
hepatektomi ( $n=1)$, mezokavalşant $(n=1)$, böbrek nakli $(n=1)$ ] $\mathrm{CH}$ olan bir hasta (\%2.6, karaciğer nakli) ve KK olan 13 hasta [\%33.3, 11 hastaya Roux-En-Y operasyonu (altısına koledokojejunostomi, beşine hepatiko-jejunostomi), bir hastaya kistoenterostomi, birine kistektomi ve beraberinde $T$ tüp drenaj] opere edildi. KK olan iki hasta ise opere edilemeden takipten çıktı.

Otozomal resesif polikistik böbrek hastalığı olan altı hastaya klinik bulguların yanı sıra genetik inceleme de yapıldı. Iki hastamizda PKHD1 geninde homozigot varyant [c.9878A>T (p.Asp3293Val), 10909C>T (p.Arg3637Cys)] tespit edildi. İkisi kardeş dört hastamızda ise compound heterozigot varyantlar [c.3306_3305delT (p.Tyr1102*)/c.4870C>T (p.Arg1624Trp) ve c.4292G>A (p.Cys1431Tyr)/c.5513A>G (p.Tyr1838Cys)] tespit edildi.

Takip edilen 39 hastanın; altısında PHT [\%15.4, Özofagus varisi $(n=5)]$, beşinde kronik böbrek yetmezliği (\%12.8), dördünde kompanse kronik karaciğer hastalığı (\%10.3) ve birinde tekrarlayan kolanjit atakları (\%2.6) mevcuttu. $\mathrm{CH}$ olan bir hastaya, tekrarlayan kolanjit atakları ve dekompanse siroz nedeniyle karaciğer nakli, KHF olan bir hastaya ise juvenil nefronofitizis ve son dönem böbrek yetmezliği nedeniyle böbrek nakli yapıldı. CH'si olan iki hasta yenidoğan döneminde ağır böbrek yetmezliği nedeniyle, KHF olan bir hasta ise karaciğer nakil sonrasında sepsis nedeniyle kaybedildi. Kalan 20 hasta sağlıklı olarak izlenmektedir. Hastaların demografik özellikleri, klinik-laboratuvar bulguları, tedavi yaklaşımları ve son durumları Tablo l'de gösterilmiştir.

\section{TARTIŞMA}

Bu çalışmada; i) çocuklarda KFKH'nın yenidoğan döneminden adölesan yaş grubuna uzanan geniş bir yaş aralığında görülebildiği, ii) özellikle KHF ve CH'de ORPBH bașta olmak üzere ekstrahepatik organ tutulumlarının görülebildiği, iii) uzun dönemde kronik komplikasyonların eşlik edebildiği ve bazı olgularda organ nakil intiyacı olabileceği tespit edilmiştir.

Karaciğer fibrokistik hastalıklarında, renal tutulum hastaların çoğuna eşlik etmektedir ve hepatorenal fibrokistik hastalıklar olarak adlandırımaktadır. Bu hastalarda en sı ORPBH-ODPBH ve ardından nefronofitizis görülmekte, hatta ORPBH-ODPBH olan vakaların tamamında, doğumdan itibaren mikroskopik düzeyde karaciğer tutulumunun olduğu düşünülmektedir (6). Bu hastalar yaşamın erken döneminde asemptomatik olabileceği gibi ilerleyen dönemde splenomegali, varis ve siroz gibi kronik komplikasyonlar ile başvurabilmektedirler $(7,8)$. Bizim hastalarımızın yaklaşık yarısında renal tutulum (ORPBH, medüller sünger böbrek, juvenil nefronofitizis) vardı. Beş hastada kronik böbrek yetmezliği mevcut olup bir hastaya böbrek nakli yapıldı. ORPBH, çoğunlukla KHF olan hastalarda görülmekteydi.
$\mathrm{CH}$ olan iki yenidoğan hasta ağır böbrek yetmezliği nedeniyle kaybedildi. KFKH'de renal tutulum sıklikla görülmekte olup bu durum ilerleyen dönemde ciddi morbidite ve mortaliteye neden olabilmektedir. Bu nedenle hastalar renal tutulum açısından yakın takip edilmelidir.

Karaciğerin fibrokistik hastalıklarının patogenezinde siliyopati olduğu için nefronofitizis, Meckel grubel sendromu, Bardet-Biedl sendromu, Joubert sendromu, Arnold chiarimal formasyonu, torasik displazi gibi birçok hastallk görülebilmektedir (8). Park ve arkadaşlarının yapmış olduğu bir çalışmada; KFKH olan 36 çocuk hasta incelenmiş ve 16 hastada (\%44) ORPBH (çoğu hastada KHF), 11 hastada (\%30.6) nefronofitizis (çoğu hastada $\mathrm{CH}), 4$ hastada (\%11.1) Meckel gruber sendromu ve 5 hastada (\%13.9) kronik böbrek yetmezliği tespit edilmiştir. ORPBH olan grupta başka organ tutulumu görülmemiş olup diğer gruplarda belirgin göz ve sinir sistemi tutulumu saptanmıştır (9). Bizim çalışmamızda da, Park ve ark. (9) çalışmasına benzer şeklide en sık görülen renal patoloji ORPBH'di ve bu hastalarda ekstrahepatik tutulum yoktu. Ancak sendromik KHF'li vakalarda; SSS, iskelet ve solunum sistemi tutulumu eșlik etmekteydi.

Fibrokistik karaciğer hastalığı olan hastalarda tekrarlayan kolanjit, intrahepatik taş, biliyer siroz ve kolanjiokarsinom riski artmaktadır. Bu hastalıkların kronik izlemde karaciğer ve/veya böbrek nakil intiyacı olabilmektedir (10). Ko ve ark. (11) yaptığı bir çalsşmada; karaciğer nakli yapılan 158 pediatrik hasta incelenmiş ve dört hastada Caroli sendromu, iki hastada KHF ve bir hastada $\mathrm{CH}$ tespit edilmiştir. En sık eșlik eden renal anomali ORPBH $(n=3)$ ve nefronofitizis $(n=1)$ olup bir hastaya kombine karaciğer/böbrek nakli yapılmıştır. Nakil endikasyonları ise tekrarlayan kolanjit, dekompanse siroz ve refrakter komplikasyonlarla seyreden PHT olarak belirlenmiştir. Caroli sendromu ve KHF olan 40 çocuk hastada yapılan başka bir çalısmada; hastaların \%35'i yenidoğan döneminde semptomatik (renal veya pulmoner) olup takipleri sırasında, \%86'sında ağır PHT, \%27'sinde GiS kanama geliştiği görülmüştür (12). Bizim çalışmamızda, hastaların yaklaşık yarısında, PHT ve özofagus varis kanaması, tekrarlayan kolanjit atakları, kronik böbrek yetmezliği gibi kronik komplikasyonlar mevcuttu. Dekompanse siroz ve son dönem böbrek yetmezliği nedeniyle üç hastaya organ nakli yapıldı.

Koledok kistleri; safra kanalının bir veya daha fazla segmentinde, kistik dilatasonlarla seyreden konjenital bir hastalığı olup KFKH alt gruplarından biridir. Etiyopatogenez tam bilinmemektedir. Ancak bir çalışmada; KK olan hastaların kist sıvısında reovirus RNA tespit edilmiştir (13). Ayrıca immun-histokimyasal çalışmalarda epitelde nitrik oksit sentaz ekspresyonunun yüksek olduğu, pankreatik enzimlerin regüjitasyonu sonucu mukozal hiperplazi ve malign değişikliklerin oluşabileceği savunulmaktadır (14). Bu hastalargeneldeantenatal USG ile tanı alılar. Tanının geç konması halinde portal ven trombozu, perforasyon, bilier peritonit, siroz gibi komplikasyonlar gelişebilmektedir. Sıklıkla yaşamın ilk aylarında kolestaz ile başvurmakta, daha ileri yaşlarda ise aralıklı 
sarılık, kolanjit, kitle ile başvurabilmektedirler. Bu hastalarda başka organ tutulumu nadirdir ve hastalar operasyon ile kür olabilmektedir (1). Bizim çalışmamızda, KK olan hastaların çoğu yenidoğan döneminde sarılık ile başvurmuştu. Ancak adölesan döneme kadar asemptomatik seyreden olgular da vardı. Bu nedenle adölesan dönemde sarılık ile başvuran hastaların ayırıcı tanısında nadir de olsa koledok kistleri düşünülmeli ve radyolojik inceleme yapılmalıdır.

\section{SONUÇ}

Karaciğerin fibrokistik hastalıkları tüm yaş grubunda görülebilen ve morbiditesi yüksek olan bir hastalık grubudur. Multisistemik tutulumun eşlik ettiği bu hastalarda, ileri dönemde siroz, PHT, kronik böbrek yetmezliği gibi komplikasyonlar gelişebilmekte ve hastaların organ nakil ihtiyacı olabilmektedir. Bu nedenle erken tanı, düzenli takip ve tedavi önemlidir.

\section{KAYNAKLAR}

1. Veigel MC, Prescott-Focht J, Rodriguez MG, Zinati R, Shao L, Moore CAW, et al. Fibropolycystic liver disease in children. Pediatr Radiol 2009; 39:317-27.

2. Bayraktar Y. Experience of a single center with congenital hepatic fibrosis: A review of the literature. World J Gastroenterol 2010;16: 683-90.

3. Drenth JP, Chrispijn M, Bergmann C. Congenital fibrocystic liver diseases. Best Pract Res Clin Gastroenterol 2010;24:573-84.

4. Terada T, Nakanuma Y. Detection of apoptosis and expression of apoptosis-related proteins during human intrahepatic bile duct development. Am J Pathol 1995;146:67-74

5. Wehrman A, Kriegermeier A, Wen J. Diagnosis and Management of Hepatobiliary Complications in Autosomal Recessive Polycystic Kidney Disease. Front Pediatr 2017;5:124.

6. Gunay-Aygun M, Avner ED, Bacallao RL, Choyke PL, Flynn JT, Germino GG, et al. Autosomal recessive polycystic kidney disease and congenital hepatic fibrosis: summary statement of a first National Institutes of Health/Office of Rare Diseases conference. J Pediatr 2006;149:159-64.

7. Carrim ZI, Murchison JT. The prevalence of simple renal and hepatic cysts detected by computed tomography. Clin Radiol 2003;58: 626-9.

8. Rock N, McLin V. Liver involvement in children with ciliopathies. Clin Res Hepatol Gastroenterol 2014;38:407-14.

9. Park E, Lee JM, Ahn YH, Kang HG, Ha II, Lee JH, et al. Hepatorenal fibrocystic diseases in children. Pediatr Nephrol 2016;31:113-9.

10. De Kerckhove L, De Meyer M, Verbaandert C, Mourad M, Sokal E, Goffette P, et al. The place of liver transplantation in Caroli's disease and syndrome. Transpl Int 2006;19:381-8.

11. Ko JS, Yi NJ, Suh KS, Seo JK. Pediatric liver transplantation for fibropolycystic liver disease. Pediatr Transplant 2012;16:195-200.

12.Gunay-Aygun M, Font-Montgomery A, LukoseL, Tuchman Gerstein M, Piwnica-Worms K, Choyke P, et al. Characteristics of congenital hepatic fibrosis in a large cohort of patients with autosomal recessive polycystic kidney disese. Gastroenterology 2013;144:112-21.

13.Tyler KL, Sokol RJ, Oberhaus SM, Le M, Karrer FM, Narkewicz $M R$, et al. Detection of reovirus RNA in hepatobiliary tissues from patients with extrahepatic biliary atresia and choledochal cysts. Hepatology 1998;27:1475-82.

14.Zhan JH, Hu XL, Dai CJ, Niu J, Gu JQ. Expressions of p53 and inducible nitric oxide synthase in congenital choledochal cysts. Hepatobiliary Pancreat Dis Int 2004;3:120-3. 